\title{
MINIREVIEW
}

\section{The $\alpha_{M} \beta_{2}$ integrin and its role in neutrophil function}

\author{
ZHANG Li \\ Department of Vascular Biology, American Red Cross, Hol- \\ land Laboratory, 15601 Crabbs Branch Way, Rockville, MD \\ 20855 USA \\ Tel: 301-738-0657 Fax: 301-738-0465 \\ e-mail:zhangl@usa.redcross.org
}

\begin{abstract}
Neutrophils are the first cell type to arrive at the injury sites and play a critical role in host defense, by virtue of its ability to adhere and transmigrate through endothelium, to phagocytose foreign pathogens, and to produce free oxygen radicals and proteolytic enzymes. Yet, inappropriate neutrophil activation causes tissue damage and various inflammatory diseases. These physiological and pathological functions of neutrophils depend on the engagement of certain surface receptors, especially $\alpha_{M} \beta_{2}$, the major $\beta_{2}$ integrin receptor present on neutrophil surface. Understanding of the molecular mechanisms underlying ligand binding by $\alpha_{M} \beta_{2}$, as well as the roles of $\alpha_{M} \beta$-ligand interactions in neutrophil functions will enable us to regulate more precisely neutrophil activities: that is, to promote their host defense functions, and at the same time to minimize their deleterious effects on normal cells.
\end{abstract}

Key words: Leukocyte, integrin, receptor, adhesion.

\section{INTRODUCTION}

Neutrophils play key roles in the host defense network against pathogens by virtue of their abilities to phagocytose microorganisms and to produce oxygen free radicals

ABREVIATIONS: EC, endothelial cell; Fg, fibrinogen; ICAM, intracellular adhesion molecule; leukocyte Adhesion Deficiency; mAb, monoclonal antibody. 
The $\alpha_{M} \beta_{2}$ integrin and its role in neutrophil function

and proteolytic enzymes. Extravasation of neutrophils from the blood stream proceeds through three coordinated steps: rolling and tethering, firm adhesion, and transmigration[1]. The first step depends on the selectin molecules expressed on both neutrophils and endothelial cells (EC)[2],[3]. The second step is mediated through interactions of the $\beta_{2}$ integrins [4], $\alpha_{L} \beta_{2}$ and $\alpha_{M} \beta_{2}$, present on the neutrophils and their counter receptors, ICAM-1 and ICAM-2, on the EC. Neutrophil-EC interaction can also be mediated by fibrinogen (Fg)[5]. ICAMs bind directly to $\alpha_{L} \beta_{2}$ [6] and aMb2[7], whereas Fg bridges neutrophils and EC by binding to $\alpha_{M} \beta_{2}$ and ICAM-1[5]. Neutrophils from patients with Leukocyte Adhesion Deficiency (LAD) fail to adhere and transmigrate through EC, resulting in life-threatening bacterial and fungal infections[8]. The role of $\alpha_{M} \beta_{2}$ in neutrophil adhesion and transmigration has been well demonstrated in animal models using function blocking mAbs[9-11], $\alpha_{M} \beta_{2}$ inhibitors[12], and $\alpha_{M} \beta_{2}$-deficient mice[13],[14].

\section{Neutrophils and their associated diseases}

Despite the essential role of neutrophils in host defense, inappropriate neutrophil activation has detrimental consequences[15]. The superoxide radicals and proteolytic enzymes produced by activated neutrophils cause ischemia/reperfusion injury and tissue damage[16],[17]. In addition, activated neutrophils produce a multitude of cytokines [18],[19] which initiate and sustain the chronic inflammatory process, leading to the development of various autoimmune diseases[16],[20]. Consistent with these deleterious effects, blockade of $\alpha_{M} \beta_{2}$-mediated ligand recognition by neutrophils using mAbs or inhibitors decreases ischemia/reperfusion injury[21],[22], reduces myocardial infarction size, myocardial necrosis[23], and liver cell injuries[24], and diminishes neointimal thickening and restenosis after angioplasty[25]. The $\alpha_{M} \beta_{2}$ blocking mAbs are also effective in the treatment of gram-negative sepsis and hemorrhagic shock[26]. Although therapies using these function-blocking antibodies are very promising, nonselective blockade of all leukocyte functions, such as neutrophil activation, transmigration, and phagocytosis, also leads to severe complications, such as bacteriall and fungal infections[27].

\section{The $\alpha_{M} \beta_{2}$ integrin recognizes multiple ligands}

$\alpha_{M} \beta_{2}$, a heterodimeric surface receptor, belongs to the $\beta_{2}$ integrin subfamily. These "leukocyte" integrins are composed of a common $\beta_{2}$ subunit noncovalently linked to one of four distinct yet highly homologous a subunits, $\alpha L, \alpha M, \alpha X$, and $\alpha D$ [28], [29]. $\alpha_{M} \beta_{2}$ is expressed by neutrophils, monocytes and NK cells, and recognizes a multitude of very different protein and nonprotein ligands. These multiple interactions provide a molecular basis for the versatile roles of neutrophils and monocytes in host defense. Protein ligands for $\alpha_{M} \beta_{2}$ include extracellular matrix proteins such as fibronectin, laminin, collagen and vitronectin[30]; counter-receptors of the immunoglobulin super- 
family such as ICAM-1[31] and ICAM-2[32]; blood coagulation proteins such as fibrinogen[33], factor X[34], and kininogen[35]; and the complement pathway product, C3bi[36]; as well as haptoglobin[37], denatured albumin[38], KLH[39], myoloperoxidase [40] and elastase[41]; non-protein ligands for $\alpha_{M} \beta_{2}$ include LPS[42], zymosan, $\beta$ glycans[43], heparin[44],[45] and oligodeoxynucleotide[46]. In addition, a variety of microorganisms produce $\alpha_{M} \beta_{2}$ ligands (e.g. NIF[47], WI-1[48] and gp63[49]) as a means of subverting or bypassing host defense mechanisms [50]. Unlike certain integrins in the $\beta_{1}$ and 3 sub-families, where a single receptor interacts with many different proteins through the common RGD sequence[51], the $\alpha_{M} \beta_{2}$ ligands share few, if any, similarities or conserved sequences. The molecular structure of the $\alpha_{M} \beta_{2}$ receptor that enables it to interact with many unrelated ligands is not yet clear, nor are the physiological functions of these interactions.

\section{Structural basis of $a m \beta$-ligand interactions}

At least five structural domains exist in $\alpha_{M} \beta_{2}$ : the I-domain, the cation-binding repeats, and the lectin binding domain in the a subunit, and the putative I-domain and the protease resistant cysteine-rich region in the b subunit. The I-domain is a region of $\sim 200$ amino acids and is found only in certain integrin a subunits. The crystal structure of the $\alpha M I$-domain was solved[52] and was shown to contain seven helices and six b sheets connected by short surface loops. Five residues located within several of these loops form a novel cation binding site, termed the MIDAS motif[52]. Recently, structures of other I-domains were determined. a-helices/b-sheets folds similar to those of the $\alpha M I$-domain have been observed[53-55]. The role of the I-domains in the ligand binding has been well established. Diamond, et al[56], find that binding of C3bi and ICAM-1 to $\alpha_{M} \beta_{2}$ is blocked by mAbs to the aMI-domain, suggesting a spatial proximity between these ligand-binding sites. We[57] and others[58], [59] showed that the recombinant aMI-domain interacts with NIF, ICAM-1, C3bi, and Fg. The importance of the Idomain in ligand binding has also been demonstrated in other integrins $\left(\alpha_{L} \beta_{2}, \alpha_{X} \beta_{2}\right.$, $\alpha_{2} \beta_{1}$ and $\alpha_{1} \beta_{1}$ )[60-63]. Given the similarity of the I-domain structures, it is not well understood how I-domains can recognize a multitude of very different proteins. Previous studies have shown that five amino acids (Asp ${ }^{140}, \mathrm{Ser}^{142}, \mathrm{Ser}^{144}, \mathrm{Asp}^{242}$, and $\mathrm{Thr}{ }^{209}$ ), conserved within essentially all I-domains, are critical to ligand-binding activity of all I-domain-containing integrins[52],[64-68], regardless of the nature of their ligands. Thus, the specificity of each integrin, which is vital to its individual in vivo roles, can not be derived from these conserved residues. To determine the molecular basis for integrin $\alpha_{M} \beta_{2}$ to interact with multiple ligands, we have used the Homologue- Scanning Mutagenesis approach[69] and systematically probed the entire outer hydrated surface of the I-domain of aM. We found that overlapping but non-identical regions within the I-domain are involved in recognition of different ligands by the $\alpha_{M} \beta_{2}$ receptor[70]. We have further mapped the ligand binding pocket for NIF to a narrow region composed of 
The $\alpha_{M} \beta_{2}$ integrin and its role in neutrophil function

Pro $^{147}-\mathrm{Arg}^{152}$, Pro ${ }^{201}$-Lys $^{217}$, and Asp ${ }^{248}$ - Arg ${ }^{261}$ of $\alpha m[71]$.

In addition to the I-domain, the cation binding repeats in integrin a subunits also have been implicated in ligand binding. D' Souza, et al, first implicated the second cation-binding repeat of aIIb in $\alpha_{I I b} \beta_{3}$ binding of the Fg- $\gamma$ chain[72]. The cation-binding repeats of $\alpha_{M} \beta_{2}$ are also important in ligand binding. Altieri, et al, showed that a mAb (OKM1) recognizing an epitope in the cation-binding repeat[56], completely blocked Fg binding to $\alpha_{M} \beta_{2}$ [73]. Other antibodies mapped to the cation-binding repeats have potent inhibitory effects on ICAM-1 binding to $\alpha_{M} \beta_{2}$ [56]. In contrast, antibodies recognizing the region between the cation-binding repeats and the transmembrane region are poor inhibitors of $\alpha_{M} \beta_{2}$ functions, and are presumed not to be directly involved in ligand interaction[56]. The involvement of the cation-binding repeats in ligand recognition was also illustrated in $\alpha_{L} \beta_{2}$ and $\alpha_{2} \beta_{1}$ using recombinnt fragments[61],[74]. Springer has recently proposed, based on computational analysis, that the region surrounding the cation-binding repeats folds into a $\beta$-propeller-like structure[75]. Though very appealing, this model is yet to be confirmed directly with experimental data. To this end, several recent studies have provided encouraging data consistent with this model [76],[77]. The ultimate test of this model will rely on structural studies using either Xray crystallography or two-dimensional NMR.

In addition to the a subunit, binding of some ligands requires cooperation from the bsubunit as well. Similar to aIIb $\beta_{3}$, the homologous $\mathrm{D}^{134} \mathrm{XSXS}$ sequence within $\beta_{2}$ is also important for $\alpha_{M} \beta_{2}$ binding to C3bi, Fg, and ICAM-1. Mutations of these oxygenated residues into Ala abolished $\alpha_{M} \beta_{2}$ binding to these three ligands[70],[78],[79]. Thus, $\alpha_{M}$ $\beta_{2}$-ligand interaction involves discrete regions within the I-domain and the $\beta$-propeller of the a subunit, as well as the $\beta_{2}$ subunit. Further studies are required to ascertain the exact roles of these different regions of $\alpha_{M} \beta_{2}$ in ligand binding.

\section{Conclusion}

$\alpha_{M} \beta_{2}$ is involved intimately in every aspects of neutrophil functions, by virtue of its ability to recognize multiple different protein and non-protein ligands. The molecular basis that confers $\alpha_{M} \beta_{2}$ with such extraordinary capability is, in part, an overlapping but non-identical ligand binding pocket, and involves the cooperation between the Idomain and the $\beta$-propeller region, as well as the $\beta$-subunit. Understanding of the molecular basis of $\alpha_{M} \beta_{2}$-ligand interactions will enable us to precisely control neutrophil functions, that is, to avoid the deleterious effects of neutrophil activation while keeping intact its host defense function.

\section{ACKNOWLEDGEMENT}

This work was supported by grants from the Arthritis Foundation and the American Heart Association. 


\section{Zhang L}

\section{REFERENCES}

[1] Springer TA. Traffic signals on endothelium for lymphocyte recirculation and leukocyte emigration. Annu Rev Physiol 1995; 57:827-72.

[2] Lawrence MB, Springer TA. Leukocytes roll on a selectin at physiologic flow rates: Distinction from and prerequisite for adhesion through integrins. Cell 1991; 65:859-73.

[3] Diacovo TG, Roth SJ, Buccola JM, Bainton DF, Springer TA. Neutrophil rolling, arrest, and transmigration across activated, surface-adherent platelets via sequential action of $\mathrm{P}$-selectin and the $\beta_{2}$ integrin CD11b/CD18. Blood 1996; 88:146-57.

[4] Smith CW, Marlin SD, Rothlein R, Toman C, Anderson DC. Cooperative interactions of LFA-1 and Mac-1 with intercellular adhesion molecule- 1 in facilitating adherence and transendothelial migration of human neutrophils in vitro. J Clin Invest 1989; 83:2008-17.

[5] Languino LR, Plescia J, Duperray A, et al. Fibrinogen mediates leukocyte adhesion to vascular endothelium through an ICAM-1-dependent pathway. Cell 1993; 73:1423-34.

[6] Dustin ML, Springer TA. Lymphocyte function-associated antigen (LFA-1) interaction with intercellular adhesion molecule-1 (ICAM-1) is one of at least three mechanisms for lymphocyte adhesion to cultured endothelial cells. J Cell Biol 1988; 107:321-31.

[7] Diamond MS, Staunton DE, de Fougerolles AR, et al. ICAM-1 (CD54)-a counter-receptor for MAC1 (CD11b/CD18). J Cell Biol 1990; 111:3129-39.

[8] Schmalstieg FC. Leukocyte adherence defect. Pediatr Infect Dis J 1988; 7:867-72.

[9] Gao J-X, Issekutz AC. Mac-1 (CD11b/CD18) is the predominant $\beta_{2}$ (CD18) integrin mediating human neutrophil migration through synovial and dermal fibroblast barriers. Immunology 1996; 88:46370.

[10] Issekutz AC, Issekutz TB. The contribution of LFA-1 (CD11a/CD18) and MAC-1 ( CD11b/CD18) to the in vivo migration of polymorphonuclear leukocytes to inflammatory reactions in the rat. Immunology 1992; 76:655-61.

[11] Graf JM, Smith CW, Mariscalco MM. Contribution of LFA-1 and Mac-1 to CD18-dependent neutrophil emigration in a neonatal rabbit model. J Appl Physiol 1996; 80:1984-92.

[12] Barnard JW, Biro MG, Lo SK, et al. Neutrophil inhibitory factor prevents neutrophil-dependent lung injury. J Immunol 1995; 155:4876-81.

[13] Coxon A, Rieu P, Barkalow FJ, et al. A novel role for the $\beta_{2}$ integrin CD11b/CD18 in neutrophil apoptosis: a homeostatic mechanism in inflammation. Immunity 1996; 5:653-66.

[14] Lu H, Smith CW, Perrard J, et al. LFA-1 is sufficient in mediating neutrophil emigration in Mac-1 deficient mice. J Clin Invest 1997; 99:1340-50.

[15] Weiss SJ. Tissue destruction by neutrophils [see comments]. N Engl J Med 1989; 320:365-76.

[16] Albelda SM, Smith CW, Ward PA. Adhesion molecules and inflammatory injury. FASEB J 1994; 8: 504-12.

[17] von Asmuth EJ, van der Linden CJ, Leeuwenberg JF, Buurman WA. Involvement of the CD11b/ CD18 integrin, but not of the endothelial cell adhesion molecules ELAM-1 and ICAM-1 in tumor necrosis factor-a-induced neutrophil toxicity. J Immunol 1991; 147:3869-75.

[18] Meda L, Gasperini S, Ceska M, Cassatella MA. Modulation of proinflammatory cytokine release from human polymorphonuclear leukocytes by gamma interferon. Cell Immunol 1994; 157:44861.

[19] Au BT, Williams TJ, Collins PD. Zymosan-induced IL-8 release from human neutrophils involves activation via the CD11b/CD18 receptor and endogenous platelet-activating factor as an autocrine modulator. J Immunol 1994; 152:5411-9.

[20] Kitsis E, Weissmann G. The role of the neutrophil in rheumatoid arthritis. Clin Orthop 1991; 6372.

[21] Jaeschke H, Farhood A, Bautista AP, Spolarics Z, Spitzer JJ, Smith CW. Functional inactivation of 
The $\alpha_{M} \beta_{2}$ integrin and its role in neutrophil function

neutrophils with a Mac-1 (CD11b/CD18) monoclonal antibody protects against ischemia-reperfusion injury in rat liver. Hepatology 1993; 17:915-23.

[22] Simpson PJ, Todd RF, III, Fantone JC, et al. Reduction of experimental canine myocardial reperfusion injury by a monoclonal antibody (Anti-Mo1, Anti-CD11b) that inhibitis leukocyte adhesion. J Clin Invest 1988; 81:624-9.

[23] Curtis WE, Gillinov AM, Wilson IC, et al. Inhibition of neutrophil adhesion reduces myocardial infarct size. Ann Thorac Surg 1993; 56:1069-72.

[24] Jaeschke H, Farhood A, Smith CW. Neutrophil-induced liver cell injury in endotoxin shock is a CD11b/CD18-dependent mechanism. Am. J Physiol 1991; 261:G1051-G1056

[25] Rogers C, Edelman ER, Simon DI. A mAb to the $\beta_{2}$-leukocyte integrin Mac-1 (CD11b/CD18) reduces intimal thickening after angioplasty or stent implantation in rabbits. Proc Natl Acad Sci USA 1998; 95:10134-9.

[26] Burch RM, Noronha-Blob L, Bator JM, Lowe VC, Sullivan JP. Mice treated with a leumedin or antibody to Mac-1 to inhibit leukocyte sequestration survive endotoxin challenge. J Immunol 1993; 150:3397-403.

[27] Ramamoorthy C, Sasaki SS, Su DL, Sharar SR, Harlan JM, Winn RK. CD18 adhesion blockade decreases bacterial clearance and neutrophil recruitment after intrapulmonary E. coli, but not after S. aureus. J Leukoc Biol 1997; 61:167-72.

[28] Springer TA. Adhesion receptors of the immune system. Nature 1990; 346:425-34.

[29] Arnaout MA. Structure and function of the leukocyte adhesion molecules CD11/CD18. Blood 1990; 75:1037-50.

[30] Bohnsack JF, Zhou X-N. Divalent cation substitution reveals CD18- and very late antigen-dependent pathways that mediate human neutrophil adherence to fibronectin. J Immunol 1992; 149: 1340-7.

[31] Diamond MS, Staunton DE, Marlin SD, Springer TA. Binding of the integrin Mac-1 (CD11b/CD18) to the third immunoglobulin-like domain of ICAM-1 (CD54) and its regulation by glycosylation. Cell 1991; 65:961-71.

[32] Xie J, Li R, Kotovuori P, et al. Intercellular adhesion molecule-2 (CD102) binds to the leukocyte integrin CD11b/CD18 through the A domain. J Immunol 1995; 155:3619-28.

[33] Altieri DC, Agbanyo FR, Plescia J, Ginsberg MH, Edgington TS, Plow EF. A unique recognition site mediates the interaction of fibrinogen with the leukocyte integrin Mac-1 (CD11b/CD18). J Biol Chem 1990; 265:12119-22.

[34] Altieri DC, Edgington TS. The saturable high affinity association of factor X to ADP-stimulated monocytes defines a novel function of the Mac-1 receptor. J Biol Chem 1988; 263:7007-15.

[35] Wachtfogel YT, DeLa Cadena RA, Kunapuli SP, et al. High molecular weight kininogen binds to Mac-1 on neutrophils by its heavy chain (domain 3) and its light chain (domain 5). J Biol Chem 1994; 269:19307-12.

[36] Ross GD, Lambris JD. Identification of a C3bi-specific membrane complement receptor that is expressed on lymphocytes, monocytes, neutrophils, and erythrocytes. J Exp Med 1982; 155:96-110.

[37] El Ghmati SM, Van Hoeyveld EM, Van Strijp JG, Ceuppens JL, Stevens EA. Identification of haptoglobin as an alternative ligand for CD11b/CD18. J Immunol 1996; 156:2542-52.

[38] Davis GE. The Mac-1 and p150, $95 \beta_{2}$ integrins bind denatured proteins to mediate leukocyte cellsubstrate adhesion. Exp Cell Res 1992; 200:242-52.

[39] Shappell SB, Toman C, Anderson DC, Taylor AA, Entman ML, Smith CW. Mac-1 (CD11b/CD18) mediates adherence-dependent hydrogen peroxide production by human and canine neutrophils. $\mathrm{J}$ Immunol 1990; 144:2702-11.

[40] Johansson MW, Patarroyo M, Oberg F, Siegbahn A, Nilsson K. Myeloperoxidase mediates cell adhesion via the $\alpha_{M} \beta_{2}$ integrin (Mac-1, CD11b/CD18). J Cell Sci 1997; 110 (Pt 9):1133-9.

[41] Cai TQ, Wright SD. Human leukocyte elastase is an endogenous ligand for the integrin CR3 
(CD11b/CD18, Mac-1, $\alpha_{M} \beta_{2}$ ) and modulates polymorphonuclear leukocyte adhesion. J Exp Med 1996; 184:1213-23.

[42] Wright SD, Jong MT. Adhesion-promoting receptors on human macrophages recognize Escherichia coli by binding to lipopolysaccharide. J Exp Med 1986; 164:1876-88.

[43] Vetvicka V, Thornton BP, Ross GD. Soluble beta-glucan polysaccharide binding to the lectin site of neutrophil or natural killer cell complement receptor type 3 (CD11b/CD18) generates a primed state of the receptor capable of mediating cytotoxicity of iC3b-opsonized target cells [see comments]. J Clin Invest 1996; 98:50-61.

[44] Diamond MS, Alon R, Parkos CA, Quinn MT, Springer TA. Heparin is an adhesive ligand for the leukocyte integrin Mac-1 (CD11b/CD18). J Cell Biol 1995; 130:1473-82.

[45] Coombe DR, Watt SM, Parish CR. Mac-1 (CD11b/CD18) and CD45 mediate the adhesion of hematopoietic progenitor cells to stromal cell elements via recognition of stromal heparan sulfate. Blood $1994 ; 84: 739-52$.

[46] Benimetskaya L, Loike JD, Khaled Z, et al. Mac-1 (CD11b/CD18) is an oligodeoxynucleotide-binding protein [see comments]. Nat Med 1997; 3:414-20.

[47] Moyle M, Foster DL, McGrath DE, et al. A hookworm glycoprotein that inhibits neutrophil function is a ligand of the integrin CD11b/CD18. J Biol Chem 1994; 269:10008-15.

[48] Newman SL, Chaturvedi S, Klein BS. The WI-1 antigen of Blastomyces dermatitidis yeasts mediates binding to human macrophage CD11b/CD18 (CR3) and CD14. J Immunol 1995; 154:753-61.

[49] Russell DG, Wright SD. Complement receptor type 3 (CR3) binds to an Arg-Gly-Asp-containing region of the major surface glycoprotein, gp63, of Leishmania promastigotes. J Exp Med 1988; 168: 279-92.

[50] Isberg RR, Tran Van Nhieu G. Binding and internalization of microorganisms by integrin receptors. Trends Microbiol. 1994; 2:10-9.

[51] D'Souza SE, Ginsberg MH, Plow EF. Arginyl-glycyl-aspartic acid (RGD): a cell adhesion motif. Trends Biochem Sci 1991; 16:246-50.

[52] Lee JO, Rieu P, Arnaout MA, Liddington RC. Crystal structure of the A domain from the a subunit of integrin CR3 (CD11b/CD18). Cell 1995; 80:631-8.

[53] $\mathrm{Qu} \mathrm{A}$, Leahy DJ. Crystal structure of the I-domain from the CD11a/CD18 (LFA-1, $\alpha_{L} \beta_{2}$ ) integrin. Proc Natl Acad Sci USA 1995; 92:10277-81.

[54] Emsley J, King SL, Bergelson JM, Liddington RC. Crystal structure of the I domain from integrin alpha2beta1. J Biol Chem 1997; 272:28512-7.

[55] Bienkowska J, Cruz M, Atiemo A, Handin R, Liddington R. The von willebrand factor A3 domain does not contain a metal ion-dependent adhesion site motif. J Biol Chem 1997; 272:25162-7.

[56] Diamond MS, Garcia-Aguilar J, Bickford JK, CoríAL, Springer TA. The I domain is a major recognition site on the leukocyte integrin MAC-1 (CD11b/CD18) for four distinct adhesion ligands. J Cell Biol 1993; 120:1031-43.

[57] Muchowski PJ, Zhang L, Chang ER, Soule HR, Plow EF, Moyle M. Functional interaction between the integrin antagonist neutrophil inhibitory factor and the I domain of CD11b/CD18 [published erratum appears in J Biol Chem 1995 Mar 17;270(11):6420]. J Biol Chem 1994; 269:26419-23.

[58] Ueda T, Rieu P, Brayer J, Arnaout MA. Identification of the complement iC3b binding site in the $\beta_{2}$ integrin CR3 (CD11b/CD18). Proc Natl Acad Sci USA 1994; 91:10680-4.

[59] Zhou L, Lee DH, Plescia J, Lau CY, Altieri DC. Differential ligand binding specificities of recombinant CD11b/CD18 integrin I-domain. J Biol Chem 1994; 269:17075-9.

[60] Randi AM, Hogg N. I domain of $\beta_{2}$ integrin lymphocyte function-associated antigen-1 contains a binding site for ligand intercellular adhesion molecule-1. J Biol Chem 1994; 269:12395-8.

[61] Dickeson SK, Walsh JJ, Santoro SA. Contributions of the I and EF hand domains to the divalent cation-dependent collagen binding activity of the $\alpha_{2} \beta_{1}$ integrin. J Biol Chem 1997; 272:7661-8.

[62] King SL, Kamata T, Cunningham JA, et al. Echovirus 1 interaction with the human very late 
The $\alpha_{M} \beta_{2}$ integrin and its role in neutrophil function

antigen-2 (integrin $\alpha_{2} \beta_{1}$ ) I domain. Identification of two independent virus contact sites distinct from the metal ion-dependent adhesion site. J Biol Chem 1997; 272:28518-22.

[63] Calderwood DA, Tuckwell DS, Eble J, Kuhn K, Humphries MJ. The integrin a1 A-domain is a ligand binding site for collagens and laminin. J Biol Chem 1997; 272:12311-7.

[64] Michishita M, Videm V, Arnaout MA. A novel divalent cation-binding site in the A domain of the $\beta_{2}$ integrin CR3 (CD11b/CD18) is essential for ligand binding. Cell 1993; 72:857-67.

[65] Kamata T, Takada Y. Direct binding of collagen to the I domain of integrin a2 b1 (VLA-2, CD49b/ CD29) in a divalent cation-independent manner. J Biol Chem 1994; 269:26006-10.

[66] Kern A, Briesewitz R, Bank I, Marcantonio EE. The role of the I domain in ligand binding of the human integrin a1 b1. J Biol Chem 1994; 269:22811-6.

[67] Kamata T, Puzon W, Takada Y. Identification of putative ligand binding sites within I domain of integrin $\alpha_{2} \beta_{1}$ (VLA-2, CD49b/CD29) [published erratum appears in J Biol Chem 1996 Aug 2; 271 (31):19008]. J Biol Chem 1994; 269:9659-63.

[68] Kamata T, Wright R, Takada Y. Critical threonine and aspartic acid residues within the I domains of $\beta_{2}$ integrins for interactions with intercellular adhesion molecule 1 (ICAM-1) and C3bi. J Biol Chem $1995 ; 270: 12531-5$.

[69] Cunningham BC, Jhurani P, Ng P, Wells JA. Receptor and antibody epitopes in human growth hormone identified by homolog-scanning mutagenesis. Science 1989; 243:1330-6.

[70] Zhang L, Plow EF. Overlapping, but not identical, sites are involved in the recognition of C3bi, neutrophil inhibitory factor, and adhesive ligands by the $\alpha_{M} \beta_{2}$ integrin. J Biol Chem 1996; 271 : 18211-6.

[71] Zhang L, Plow EF. Identification and reconstruction of the binding site within $\alpha_{M} \beta_{2}$ for a specific and high affinity ligand, NIF. J Biol Chem 1997; 272:17558-64.

[72] D'Souza SE, Ginsberg MH, Matsueda GR, Plow EF. A discrete sequence in a platelet integrin is involved in ligand recognition. Nature 1991; 350:66-8.

[73] Altieri DC, Bader R, Mannucci PM, Edgington TS. Oligospecificity of the cellular adhesion receptor MAC-1 encompasses an inducible recognition specificity for fibrinogen. J Cell Biol 1988; 107:1893900.

[74] Stanley P, Bates PA, Harvey J, Bennett RI, Hogg N. Integrin LFA-1 a subunit contains an ICAM1 binding site in domains V and VI. EMBO J 1994; 13:1790-8.

[75] Springer TA. Folding of the N-terminal, ligand-binding region of integrin $\alpha$-subunits into a $\beta$ propeller domain. Proc Natl Acad Sci USA 1997; 94:65-72.

[76] Irie A, Kamata T, Takada Y. Multiple loop structures critical for ligand binding of the integrin alpha4 subunit in the upper face of the $\beta$-propeller mode 1. Proc Natl Acad Sci USA 1997; 94: 7198203.

[77] Oxvig C, Springer TA. Experimental support for a b-propeller domain in integrin a-subunits and a calcium binding site on its lower surface. Proc Natl Acad Sci U S A 1998; 95:4870-5.

[78] Loftus JC, O'Toole TE, Plow EF, Glass A, Frelinger AL, Ginsberg MH. A $\beta_{3}$ integrin mutation abolishes ligand binding and alters divalent cation-dependent conformation. Science 1990; 249: 915-8.

[79] Bajt ML, Goodman TG, McGuire SL. $\beta_{2}$ (CD18) mutations abolish ligand recognition by I domain integrins LFA-1 $\left(\alpha_{L} \beta_{2}, \mathrm{CD} 11 \mathrm{a} / \mathrm{CD} 18\right)$ and MAC-1 $\left(\alpha_{M} \beta_{2}, \mathrm{CD} 11 \mathrm{~b} / \mathrm{CD} 18\right)$. J Biol Chem 1995; 270:948. 